\title{
INTRODUCTION: CONTEMPORARY TRANSLATION STUDIES AND BIBLE TRANSLATION
}

\author{
J.A. Naudé ${ }^{1} \&$ C.H.J. van der Merwe $^{2}$
}

The need for a formal-equivalent Afrikaans Bible has been expressed in some circles in South Africa for many years. Among other things, this need prompted the interdenominational committee of churches that use the Bible in Afrikaans (The Church Advisory Committee: Afrikaans Translations) to request the Bible Society of South Africa (BSSA) to arrange a symposium on recent developments in translation studies and Bible translation that may be relevant to Bible translation in South Africa. Following developments in the United Bible Societies (UBS) in which some of the theoretical assumptions of Eugene Nida's views were questioned, an inquiry into the implications of these and other developments in contemporary translation studies for Bible translation in South Africa was certainly necessary and timely.

The BSSA approached the Centre for Bible Translation in Africa at the University of Stellenbosch to participate in drawing up the agenda for this symposium. This turned out to be a team effort in the real sense of the word. The agenda emerged after careful and close consultation between the Centre, the BSSA, the Chairperson of the Church Advisory Committee and each of the invited experts. Extreme care was taken to invite to the symposium representatives of all the potential readers of the Bible in Afrikaans, as well as academics who are involved or may be involved in Bible translation. The three-day symposium took place in Kempton Park from 20 to 22 August 2001. From the outset it became clear that there had been a shift in translation studies from which the 1983 Afrikaans Bible translation had not been able to benefit. The 1980s saw the cultural turn in translation studies with its focus on the way culture impacts and constrains translation. As a result of this development, the focus in translation studies shifted from the source text to the translation process, the product and/or reception of the translation as well as the cultural-social bound character of translation.

1 Prof. J. A. Naudé, Department of Near Eastern Studies, University of the Free State, P.O. Box 339, Bloemfontein, 9300, South Africa. E-mail: naudej@ hum.uovs.ac.za

2 Prof. Christo H. J. van der Merwe, University of Stellenbosch. E-mail: cvdm@sun.ac.za 
The methodological impact was a shift from normative linguistic-based theories of translation (e.g. the functional-equivalent approach), which dominated translation work when the 1983 Afrikaans translation came on the scene, to either functionalist approaches to translation or descriptive translation studies (DTS). Linguistic theorists regard the source text as a norm and evaluate any translation in terms of its equivalence to the source text. In contrast, the functionalist theorists regard a translation as a new communicative act that must be purposeful with respect to the translator's clients and readership, while DTS views a text as a translation if it functions as such in the receiving culture and literary system.

The articles in this volume provide a South African perspective on recent developments in translation studies as well as in the theory of Bible translation. In the first article Eric Hermanson gives a succinct overview of the history of Bible translation in South Africa. Two clearly defined periods of Bible translation in South Africa are distinguished, namely the Missionary Society Period, with formal-equivalent translations being made by missionaries, and the Bible Society Period with dynamic-/functional-equivalent translations being made by interdenominational translation teams under the guidance and supervision of the Bible Society. In the next two articles, Gert Jordaan and Stephan Joubert question the theoretical foundations of the functional-equivalent approaches to Bible translation. Jordaan finds the theoretical foundation of the functional-equivalent approach problematic, because it sees the task of the translator as making the Bible communicate to modern readers via a process of transformation of the socio-historical codes of the source text. This view of communication results in a view of the Bible as a timebound document and this is unacceptable for Jordaan. Joubert argues that the functional-equivalent approach suffers from the lack of a comprehensive engagement with the cultural meanings encoded in the original biblical documents. The aim to communicate effectively in the language of receptor cultures has produced Western translations that fit too easily into contemporary contexts. The implication is that the modern readership does not come to terms with the socio-cultural distance between the ancient Mediterranean world and contemporary contexts. Jacobus Naudé and Alet Kruger give an overview of current trends in contemporary Translation Studies that are relevant to Bible translation. After a review of developments away from functional equivalence in translation studies since the cultural turn of the early 1980s, Naudé emphasises the advantages of the functionalist approach of Christiane Nord with its focus on the intention/purpose/skopos of a translation as it follows from the translation brief. The consequence is that Bible translation is normal translation and opens 
up foreign culture. Bible translations could be created for specific purposes and translation strategies must be followed instead of striving towards equivalence. In her article, Kruger provides an overview of corpus-based translation research, which builds upon the studies of scholars working within DTS. It involves using computerised corpora to study translated text, not in terms of its equivalence to source texts, but as a valid object of study in its own right by revealing both universal and specific features of translation. She indicates that this new approach could shed light inter alia on the linguistic and textual features of different translations and/or revisions of the same Bible in respect of consistency of terminology, orthography and register; the effect of dialectal variation; interference of the source language and the translator's mother tongue; regularities and recurring patterns and typical strategies utilised.

The following group of articles provides new considerations and initiatives on the methodology of Bible translation. Kevin Smith discusses ErnstAugust Gutt's relevance theory-based approach with the aim of clarifying the central objective and main tenets of Gutt's thesis so as to construct a platform for constructive debate between adherents of functional equivalence and advocates of relevance theory. It is shown that relevance theory provides a means of predicting the conditions of communicative success in translation, thus empowering translators to predict more effectively whether or not a given rendering will communicate effectively with the target audience. Jan van der Watt and Yolande Kruger consider a translation to be a complex and creative process in which the translator should endeavour to combine and mix the various elements (for instance grammatical, structural, literary and socio-cultural) in such a way that the meaning in the target language comes as close as possible to that of the source text. Timothy Wilt explains in detail the new initiative for Bible translation of the UBS. The shortcomings of the linguistic tools in Nida \& Taber (1969) as well as in De Waard \& Nida (1986) are corrected by Bible translators looking at sociolinguistics, discourse linguistics, text linguistics, pragmatics, functional linguistics, and cognitive linguistics. The communication situations of Bible translation in Africa between the time of Nida \& Taber (1969) and today are compared and dramatic differences are found. A discussion document on problematic issues of Bible translation is included in the appendix of his article. Ernst Wendland proposes a more dynamic approach to Bible translation as one possible option, should this be called for by the contextual circumstances of the target language setting. His method features a genre-based, functional application of interlingual discourse analysis and representation that aims to reproduce the literary (poetic) quality of the 
original text within a new linguistic and socio-cultural environment. Aloo Mojola highlights the implications of the above-mentioned developments for Bible translation in Africa. Special focus is given to the shifts that have occurred with respect to its vision and mission. Kees de Blois, chairperson of the New Dutch translation project, and Tamara Mewe, point out some of the lessons that can be learned from their project. It is a team approach including 60 representatives of 22 churches or faith communities including the Jewish community. The aim of the project is to complete a standard translation for use in church and community for the next 20-25 years. It must be suitable for liturgical use. An interactive translation process based on trial translations and feedback is utilised. They also indicate how functional-equivalent principles had to be redefined in the light of the need for a better theoretical model.

The last group of articles indicates the way towards a new (Afrikaans) Bible translation and addresses the role of the source languages in the translation process, the process of interpretation and the language ecology of the target text, of which translators must be aware. Christo van der Merwe looks at recent developments in the field of Hebrew linguistics that are relevant to Bible translation. He points out that a new paradigm in the study of language has provided a fresh perspective on aspects of language that were up until now misunderstood, not fully appreciated, or not even noticed. Improved models of what people do with language, which include the social, cognitive and cultural aspects of language, now provide explanations for Biblical Hebrew expressions that translators up until now believed they could, or should, leave untranslated. In the light of these developments, he is of the opinion that a new translation of the Bible in Afrikaans needs to be seriously considered. Jan van der Watt deals with issues of a hermeneutic nature for consideration by translators, namely the philosophical framework of translation, some of the presuppositions and assumptions of literal translations, the intended function of a particular translation, the emphasis of a translation which determines its nature, and the role of interpretation in the translation process. Heilna $d u$ Plooy discusses the literary theories which dominated textual studies during the twentieth century. She points out that whereas theories during the greater part of the twentieth century tended to encourage a more open approach to meaning and textuality, there are clear indications of a new awareness of textual constraints in the different forms of textual processing which interpreters and translators must be aware of. On the language ecology of a new Afrikaans Bible, Fritz Ponelis indicates in the last article that three sets of codes are germane to a current Afrikaans Bible translation namely Dutch, English and varieties of Afri- 
kaans, especially Standard Afrikaans. Both the ideological linkage of the last mentioned code with Afrikaner nationalism and its marked divergence from varieties of colloquial Afrikaans bear on a new Afrikaans Bible translation.

The above-mentioned articles illustrate without doubt that translation studies, and by implication Bible translation, have entered a new era. Eugene Nida and the linguistic approaches prompted developments that raised the respectability of translation studies as an academic discipline. More recently the cognitive and culturally oriented approaches have rendered insight into the complexity of the process of translation, and, for example, identified the wide range of factors to be considered in the process of translation as an act of communication. In turn, the functionalist approaches contributed to the formulation of theoretical frames of references in terms of which particular translation activities could be verified intersubjectively.

The above-mentioned articles also clearly illustrate the fact that Bible translation is a "full-fledged" interdisciplinary activity. It involves knowledge and insight from the fields of biblical studies, translation studies as well as linguistics and the literary sciences (i.e. in both the source and target text languages). Bible translation in South Africa, where $70 \%$ of its citizens consider themselves Christians, has the benefit that it can reap from a rich tradition of the study of the Bible, and in particular Greek, Hebrew and Aramaic. Furthermore, in a country with 11 official languages, Bible translation also benefits from the fact that the study of different languages, the training of translators, and academic research in the field of translation studies enjoy a very high profile. We are of the opinion that these articles illustrate that Bible translation in South Africa faces a number of exciting challenges, challenges which the scholars of the country are ready to face, and challenges the outcome of which could make an important contribution to Bible translation on our continent.

\section{BIBLIOGRAPHY}

De WAard J \& Nida E A 1986. From one language to another. Functional equivalence in Bible Translating. Nashville: Thomas Nelson Publishers.

NIDA E A \& TABER C

1969. The theory and practice of translation. Leiden: Brill. 